\title{
UM OLHAR "BAKHTINIANO" SOBRE O CARNAVAL NA CANÇÃO "VAI PASSAR" (FRANCIS HIME E CHICO BUARQUE)
}

\author{
Elizabeth Harkot La Taille*
}

RESUMO: Partindo da premissa de que a forma mais representativa de carnaval é brasileira, este texto propõe a discussão de até que ponto a canção Vai Passar traduz a visão carnavalesca de mundo, libertária e regeneradora, encontrada em Rabelais e estudada por Bakhtin (1988/1970): inversão da ordem estabelecida, rebaixamento de valores, destituição do sagrado, celebração do renovável e dinâmico, função do riso e do tempo e seu sistema de imagens. A partir dessa análise, tecem-se considerações sobre a manifestação carnavalesca sugerida pela canção, os desfiles de escolas de samba, comparados ao carnaval da Idade Média e Renascimento.

Palavras-chave: Carnaval, cômico popular, rebaixamento, grotesco, riso.

\section{INTRODUÇÃO}

“- Brasil é a terra do Carnaval!", diz-se, como a constatação de uma terra cujo povo é festivo, livre e brincalhão. Poucos discordariam de que o carnaval de Veneza nada tem a ver com o carnaval brasileiro, que o de $\mathrm{Mu}$ nique só é famoso por contar com a presença de muitos habitantes locais brasileiros, que o de Nova Orleans não passa de uma parada singela ao lado dos desfiles de escolas de samba, etc., isso sem contar com as condições climáticas, muito mais favoráveis à exuberância, à fartura e à alegria no verão tropical do que no inverno temperado.

Ufanismo à parte, é indiscutível que o carnaval brasileiro é um grande e belo acontecimento. E é verdade que ao lado dos desfiles de escolas de samba existe um sem fim de celebrações informais, nas ruas e praças públicas, celebrações em que a multidão dança e brinca em conjunto, num clima

* Doutora pelo Departamento de Lingüística da FFLCH/USP. 

(Francis Hime e Chico Buarque). Língua e Literatura, n. 22, p. 61-73, 1996.

de liberdade. Será o carnaval brasileiro próximo ao carnaval medieval contado por Rabelais e estudado por Bakhtin? Terá o carnaval brasileiro conservado a essência do carnaval da Idade Média, essência essa libertária e regeneradora por excelência, responsável, em parte, até pelo encerramento da idade das trevas representada pelo período gótico?

Estudar o carnaval brasileiro é tarefa extensíssima, tanto por sua variedade de formas e imagens quanto pela complexidade de cada uma das formas locais. Este texto tem uma proposta modesta, que é a de fechar o ângulo de captura e fazer um close-up do carnaval através de uma canção, Vai Passar, e tecer considerações sobre a forma símbolo dos carnavais brasileiros, evocada pela canção, a dos desfiles de escolas de samba.

Sob que aspectos pode Vai Passar ser considerada uma canção representativa do carnaval?

Ela não é uma canção carnavalesca no sentido de marcha de carnaval, de música para pular carnaval, de letra simples e refrão insistente (como Mamãe, eu quero...). Não se trata, também, de uma canção popular tradicional, repetida de pais para filhos, conhecida há gerações. Além disso, é uma composição originária da elite da intelectualidade, apreciada principalmente pelas classes mais favorecidas e compreendida somente por aqueles mais politizados. Aliás, pode-se apontar, canção carnavalesca não é para ser compreendida, é para ser absorvida enquanto letra e ritmo, é para ser dançada.

Vai Passar parece ter tudo, num primeiro olhar, de canção não carnavalesca. Existe, entretanto, o outro lado dos argumentos levantados. Em primeiro lugar, não é marcha, nem é tradicional, mas relata uma história, aos moldes dos sambas de enredo. Em segundo lugar, é uma composição da elite, mas uma composição coerente com a idéia de carnaval: o narrador pertence à cena que descreve, está no mesmo nível dos acontecimentos, é observador participante, ocupando a posição de heraldo; alguém poderia pensar que por ser intelectualizada, a letra narraria algo visto do alto, de um camarote, mas o que ocorre é a perfeita integração do narrador à cena descrita. Finalmente, a letra compõe um texto coeso, tanto para aqueles que percebem apenas a história cantada, quanto para os que nela reconhecem o intertexto sociopolítico que a ela subjaz e que é por ela ativado na memória do ouvinte.

Feitas as observações acima, a análise que segue tem o objetivo de verificar se a canção encerra elementos levantados por Bakhtin no carnaval rabelaisiano. O cerne da questão a ser respondida não é se Vai Passar é ou não música de carnaval, mas se possui uma estrutura carnavalesca, no sentido bakhtiniano de carnaval. 
Para tanto, este texto está dividido em três partes: em primeiro lugar, um sobrevôo do carnaval rabelaisiano, segundo Bakhtin; em segundo, a análise e discussão da canção Vai Passar, do ponto de vista de sua organização semântico-discursiva; e, finalmente, no cotejo das duas primeiras partes, uma tentativa de resposta à questão colocada, acrescida de considerações gerais sobre o carnaval da mídia.

\section{O CARNAVAL MEDIEVAL/RENASCENTISTA}

O carnaval na Idade Média e Renascimento, por não sofrer determinações sociais e por possuir um complexo sistema de imagens, é uma manifestação privilegiada do cômico popular, considerado sua mais pura e completa expressão. O riso acompanha todas as formas de celebrações, as quais estabelecem um segundo mundo e uma segunda vida, paralelos aos oficiais, em que são abolidos todos os dogmas, religiosos ou eclesiásticos, e em que os cultos comparecem enquanto paródias, esvaziados de seu conteúdo mágico. Nesse outro universo, não existem entidades superiores ao povo, não existe santidade, nem tampouco poder. $\mathrm{O}$ inferno, atributo obrigatório do carnaval, comparece enquanto elemento cômico, de animação.

Não se trata de uma manifestação teatral artística, mas de um jogo, da vida apresentada como um jogo, em que todos participam, sem palco, sem ribalta, sem distinções; trata-se de uma manifestação vivida - não apresentada ou assistida - pelos participantes, na fronteira da arte e da vida.

"En resumé, pendant le carnaval, c'est la vie même qui joue et, pendant un certain temps, le jeu se transforme en vie même. Voilà la nature spécifique du carnaval, un mode particulier d'existence.

Le carnaval, c'est la seconde vie du peuple, basée sur le principe du rire." BAKHTIN (1988:16) ${ }^{1}$

O riso, no carnaval da Idade Média, tem caráter universal: é dirigido contra tudo o que é sério, sem recusá-lo: purifica-o, completa-o; é libertador: extra-oficial, não proibido; traz a "verdade popular não oficial" (p. 98). Não se confunde, portanto, com a ironia.

1 Todas as citações são de Bakhtin, L'Oeuvre de François Rabelais et la culture populaire au moyen âge et sous la renaissance, Collection TEL, Gallimard, France, 1988. 
Um outro aspecto relevante sobre as festividades do cômico popular, inclusive as do carnaval, é o fato de estarem sempre relacionadas a períodos de crise: mudanças de estação, nascimento/morte, mudanças sociais. Retratam as multidões, nesses momentos, tendo acesso temporário à esfera da abundância, da universalidade, da liberdade, da igualdade. O que conta é o homem enquanto espécie - a multidão, o povo -, não as individualidades. Essas festividades, opostas às oficiais - conservadoras, responsáveis pela celebração de indivíduos, da manutenção do status-quo -, elevam o carnaval a uma vitória efêmera sobre o regime, os privilégios, a hierarquia e a verdade dominantes. Durante o carnaval, a estrutura hierárquica é abolida e torna-se possível o estabelecimento de uma forma de comunicação, freqüentemente licenciosa, através da qual todos são iguais.

É próprio do carnaval tomar as coisas por seus opostos ou ao inverso: alto e baixo trocam de lugar na hierarquia; cerimônias são parodiadas e ridicularizadas; o corpo comparece enquanto rosto e traseiro, a ingestão e eliminação de alimentos são apresentadas como concomitantes, etc.; mesmo o riso carnavalesco é ambivalente: é alegre e sarcástico, divertido e crítico. Essa convivência dos opostos virá a constituir o realismo grotesco, nas palavras de Bakhtin.

"Dans le réalisme grotesque (...), le principe matériel et corporel est présenté sous son aspect universel de fête, utopique. Le cosmique, le social et le corporel sont indissolublement liés, comme un tout vivant et indivisible." (p. 28).

Característico do realismo grotesco é o fenômeno do rebaixamento, isto é, a transposição de todos os cerimoniais e ritos para o plano material, corpóreo. As imagens grotescas apresentam a fusão de dois opostos convivendo, como morte e vida, velho e novo - por exemplo, uma velha parindo -, ou noite e dia, opostos fundidos em metamorfose, em metamorfose inacabada. Apresentam o fenômeno em processo de mudança (diferentemente do grotesco romântico, em que as ambivalências se transformam em antíteses ou contrastes estáticos); desse tipo de combinação sempre resta um quadro de regeneração e esperança para o homem enquanto espécie. É através do grotesco que o carnaval medieval/renascentista pode tornar-se libertário:

“... le grotesque du Moyen Age et de la Renaissance, imprégné de la sensation carnavalesque du monde, libère ce dernier de tout ce qu'il peut y avoir de terrible et effrayant, le rend 
totalement inoffensif, joyeux et lumineux à l'extrême. Tout ce qui était terrible et effrayant dans le monde habituel se transforme dans le monde carnavalesque en joyeux "épouvantails comiques" La peur est l'expression extrême d'un sérieux unilatéral et stupide vaincu par le rire. (...) Ce n'est que dans un monde ou la peur est totalement bannie qu'est possible cette liberté extrême propre au grotesque." (p. 57)

Segundo Bakhtin, a percepção carnavalesca do mundo é contrária ao estático e estabelecido, ao imutável e eterno. O carnaval é sobretudo a celebração do renovável, dinâmico e inacabado; é uma festa voltada para o futuro, para a utopia. O carnaval, baseado no princípio do riso, realiza a vitória sobre o medo.

\section{A CANÇÃO}

A letra da canção está dividida em seis blocos, em função da análise que a segue.

\section{VAI PASSAR}

1 Vai passar

2 Nessa avenida um samba popular

3 Cada paralelepípedo

4 Da velha cidade

5 Esta noite vai

6 Se arrepiar

7 Ao lembrar

8 Que aqui passaram sambas imortais

9 Que aqui sangraram pelos nossos pés

10 Que aqui sambaram nossos ancestrais

11 Num tempo

12 Página infeliz da nossa história

13 Passagem desbotada da memória

14 Das nossas novas gerações

15 Dormia

16 A nossa Pátria mãe tão distraída

17 Sem perceber que era subtraída

$18 \mathrm{Em}$ tenebrosas transações 
19 Seus filhos

20 Erravam cegos pelo continente

21 Levavam pedras feito penitentes

22 Erguendo estranhas catedrais

23 E um dia, afinal

24 Tinham direito a uma alegria fugaz

25 Uma ofegante epidemia

26 Que se chamava carnaval

28 O carnaval, o carnaval

29 (vai passar)

30 Palmas pra ala dos barões famintos

31 O bloco dos napoleões retintos

$32 \mathrm{E}$ os pigmeus do bulevar

33 Meu Deus, vem olhar

34 Vem ver de perto uma cidade a cantar

35 A evolução da liberdade

36 Até o dia clarear

$37 \mathrm{Ai}$, que vida boa, olerê

$38 \mathrm{Ai}$, que vida boa, olará

39 O estandarte do sanatório geral vai passar

$40 \mathrm{Ai}$, que vida boa, olerê

$41 \mathrm{Ai}$, que vida boa, olará

$42 \mathrm{O}$ estandarte do sanatório geral

43 Vai passar

Análise dos blocos:

a) versos 1 a 10:

Vai passar anuncia um acontecimento festivo que se aproxima, um "samba popular" imbuído do poder de reviver coisas inertes e lembranças apagadas. Com sua passagem, (v.4-7) os velhos paralelepípedos se arrepiarão ao lembrar que (v.8-10) existem "sambas imortais", que o narrador e seus contemporâneos já os "sambaram" até além da dor física e que também seus pais, avós, enfim, seus antepassados o fizeram. O verso de abertura dirige o leitor/ ouvinte para o futuro: ganha estatuto de promessa do inevitável, como um dia após o outro, promessa de renascimento das cinzas. O que é estabelecido e sólido como paralelepípedo perderá, mesmo se momentaneamente, seu valor 
(Francis Hime e Chico Buarque). Língua e Literatura, n. 22, p. 61-73, 1996.

absoluto, num clima de grande alegria e alívio, através da ação de um "samba popular" Nestes versos, o futuro, através da música, injeta vida na morte, introduz movimento no que é estático e opera a renovação do velho. Importante observar que não serão pessoas dançando um samba que operarão a desequilíbrio de estruturas ou idéias estabelecidas, mas sim um samba popular, isto é, uma unidade externa capaz de amalgamar as individualidades numa causa comum: o sambar. Estes versos apresentam um jogo de passado e futuro imediato: o bom vem com o futuro, o ruim é representado pelo passado.

b) versos 11 a 22:

Parênteses são abertos para o passado velho (v.11) e triste (v.12), já quase esquecido (v.12/13). O passado é negro, como uma noite sem fim e sem calor, em que "Dormia/A nossa Pátria", figura materna ingênua e desatenta, aviltada, sugada, explorada (V. 15-19). Nessa noite sem fim, enquanto a "mãe" de nada se dava conta, os filhos, em abandono, seguiam como autômatos, trabalhavam duro, como escravos, por causas ilegítimas, respeitavam valores estranhos aos seus, enfim, encontravam-se perdidos, agarrando-se a ilusões (v.20-22). O tempo verbal escolhido, o pretérito imperfeito, indica um acontecimento de longa duração e cria o efeito de sentido de estaticidade, de imutabilidade, de existência de uma ordem estabelecida opressora e vencedora, ordem essa que poderia ser um hábito, uma tradição, e que, no texto, é pervertida: subjuga pátria e patrícios, mãe e filhos. Estes versos formam um quadro do anticarnaval: seriedade, tristeza, sono, escuridão, sofrimento, opressão, poder, estaticidade.

c) Versos 23 a 28 :

O carnaval é apresentado como parte excepcional, porém integrante, da rotina desse tempo passado: um direito atribuído aos homens, uma desforra. Nesse quadro do passado, é patente a separação entre os dias normais (versos 11 a 22) e o dia excepcional de alegria. Não há possibilidade de coocorrência do cotidiano e da alegria. Todavia, vê-se, adiante, que o carnaval realiza uma espécie de contaminação, é uma "epidemia" Introduz-se na rotina como um vírus, como um pequenino agente capaz de desarranjar um sistema. Só que, ao contrário dos vírus, a "epidemia" que provoca é desejada, pois resgata a alegria e deixa um gosto de liberdade, ou ao menos de distensão, na lembrança. Em meio aos tristes tempos dos versos anteriores, a esperança se deixa timidamente entrever através do carnaval. Além disso, no nível da coesão do texto, o carnaval opera a transição entre o passado e o futuro imediato, marcando, nessa direção, a orientação do tempo e deslocando o olhar do povo do passado ruim para o futuro bom. 


\section{d) Verso 29:}

Efetua-se a transição, a ligação do passado e do futuro. No texto, surge entre parênteses e, na música, é inserida entre dois compassos, como preenchendo uma pausa: opera como um chamamento, como uma palavra de ordem para que se abandone o que passou e se volte para o que vai ser. Nos versos seguintes, evidencia-se sua função: mais do que unir passado e futuro, funde esses dois opostos, por definição intangíveis, no momento passível de ser vivido, o presente.

e) Versos 30 a 36:

O carnaval. Chega o acontecimento esperado e anunciado, fusão da esperança no futuro e da lembrança do passado, na celebração do presente. Surgem aqui elementos destacados no carnaval medieval/renascentista. Nos versos 30 a 32, rebaixamento e indumentária: passam alas e blocos invertendo a hierarquia oficial. Os representantes da riqueza (barões) são, na verdade, famintos, os do poder (napoleões) são oprimidos, representados por negros, os da cultura e beleza são "pigmeus ${ }^{2}$ do bulevar" Não se trata de mera representação: os papéis são vividos, na festa, não apenas desempenhados. Nos versos 33 a 36, dessacralização: tão belo é o espetáculo apresentado que Deus é chamado para vê-lo. A festa evolui num crescendo e o ápice do volume dos instrumentos e das vozes é atingido no momento em que chega a liberdade, música e letra sustentando-se conjuntamente. Essa festa instaura também a universalidade - trata-se de "uma cidade a cantar" (grifo meu), não de indivíduos - e obtém vitória sobre o regime vigente - a liberdade se instala e evolui ${ }^{3}$, até o momento da aurora. Quando o dia clarear, a grande noite na qual o passado estava submerso - promete a canção - terá terminado, terá sido vencida.

\section{f) Versos 37 a 43 :}

A cura se faz através da festa. O que conta é aproveitar a vida, é ser feliz. No mundo paralelo estabelecido pelo carnaval a vida é boa. O samba popular possui efeito regenerador, tem poder de curar os males do povo, é o "estandarte do sanatório geral", isto é, opera como uma catarse geral através do gozo. Entretanto não se pode esquecer que na origem desta cura está a "ofegante epidemia" do verso 25 , e que epidemias são passageiras. Final-

2 Segundo Aurélio, podem também ser compreendidos como seres de baixíssima estatura e/ou talento ou cultura insignificante.

3 A evolução da liberdade pode ser compreendida tanto como desenvolvimento progressivo quanto, como em desfiles de carnaval, cada um de uma série de movimentos harmônicos que determinam a passagem de uma posição a outra. 
(Francis Hime e Chico Buarque). Lingua e Literatura, n. 22, p. 61-73, 1996.

mente, um recurso gráfico e outro musical de grande relevância lingüística operam uma mudança de perspectiva: o verso 39 termina com entoação ascendente, preparando uma frase musical circular; seu par, no entanto, traz duas surpresas: sua representação gráfica é cortada em dois versos (42 e 43), e sua entoação é descendente e precedida de uma breve pausa, de modo que o leitor/ouvinte atribui ao último "Vai passar" um sentido diferente do inicial, isto é, não mais um sentido de anúncio do que vai chegar, mas sim de constatação de que o que chegou não vai ficar, não vai durar para sempre. $O$ último verso, sendo igual ao primeiro, sugere a circularidade do acontecimento e, tendo entoação descendente, sua transitoriedade.

\section{DISCUSSÃO}

Como se pode observar, a canção é repleta de elementos carnavalescos. Aquilo que vai passar desperta a esperança do povo num futuro melhor, mais justo, numa verdade nova. É contrário à estaticidade das coisas, a situações estabelecidas, imutáveis, eternas. Surge num momento de crise, entre um passado obscuro e um suposto futuro brilhante. O carnaval de Vai Passar celebra o renovável e o dinâmico; é vivido pelos homens enquanto multidão - não indivíduos - ; rebaixa os valores para o nível terrestre e humano, invertendo ou anulando hierarquias; e destituindo o sagrado, traduz a ânsia por liberdade e dirige o olhar ao futuro. Pode-se então responder à questão inicial, se a canção possui estrutura carnavalesca?

Falta ainda abordar dois aspectos. O primeiro diz respeito ao caráter auroral do carnaval medieval, em contraste com a preferência pela noite, em Vai Passar Enquanto o primeiro, através do grotesco popular "...est par excellence printanier, matinal, auroral" (p. 50), o segundo desenvolve-se "até o dia clarear" (v. 36); com o fim da noite, a festa acaba. Se a preferência por noite ou manhã pode parecer um detalhe, ou um adereço sociocultural sem conseqüências importantes, já o segundo aspecto surge como essencial: a função que desempenha o riso no carnaval da canção. No carnaval medie$\mathrm{val} /$ renascentista sempre comparecem imagens do lado obscuro, sério, desagradável, doloroso da vida e tais imagens integram-se à festa, ao clima de festa, enquanto elementos cômicos. $\mathrm{O}$ inferno, por exemplo, funciona como um elemento de animação, não é com temor ou tristeza que ocorre sua contemplação, mas com zombaria. No texto da canção, o passado poderia ser comparado ao inferno, mas visto por olhos que o temem e o recusam. 
Enquanto no sistema de imagens da festa popular medieval não há lugar para a negação pura, enquanto as imagens procuram englobar dois pólos no devir, em Vai Passar ocorre uma interseção de dois opostos: o antes, o velho, o negativo servem de apoio para o devir, como uma lembrança de que sua consciência é necessária para a completa apreciação daquilo que vai passar. A festa pode ser apreciada parcialmente, no nível da avenida - dançando e cantando - ou totalmente, no nível da consciência de um possuidor de memória não "desbotada", ciente da importância da situação de liberdade após um longo período de opressão. É justamente a importância da situação que lhe apaga o riso e lhe impõe esse ar grave que a descaracteriza enquanto manifestação carnavalesca do tipo medieval. Tomemos como exemplo apenas a comparação dos penitentes, que carregam pedras, com os Chicanous ${ }^{4}$, habitantes de uma ilha encontrados por Pantagruel e descritos como um povo que ganha a vida deixando-se espancar: enquanto os primeiros são oprimidos e se submetem a uma penitência, os últimos parecem divertir-se com as surras que levam, rindo-se delas.

Um outro momento em que falta o riso escrachado e zombeteiro é na função da indumentária, das fantasias. No carnaval medieval/renascentista, portar fantasias tinha a mesma lógica das sagrações de reis, bispos e papas para rir. Ao sagrar o bobo rei, operava-se a inversão do alto/baixo hierárquico em direção ao baixo material (o elevado era rebaixado, o baixo não era elevado). $\mathrm{Na}$ canção, há fantasias, há inversões: os barões são famintos, os napoleões são oprimidos e no bulevar desfilam pigmeus. Mesmo existindo o caráter de rebaixamento do plano elevado, esses barões, napoleões e pigmeus do bulevar não são instituídos para provocar riso.

Por fim, voltemos às concordâncias, apontando um último aspecto comum ao carnaval medieval e ao de Vai Passar: o tempo. Nos dois, o tempo é o operador de mudanças. É o tempo o autor de destronamentos, de ridicularizações, finalmente, de por à morte o velho, dando ao mesmo tempo nascimento ao novo. O carnaval em Vai Passar não nega as duas citações abaixo:

"Les formes de la fête populaire ont les yeux tournés vers l'avenir et présentent sa victoire sur le passé, "l'âge d'or": la victoire de la profusion universelle des biens matériels, de la liberté, de l'égalité, de la fraternité. L'immortalité du peuple garantit le triomphe de l'avenir. La naissance de quelque chose

4 op. cit., p. 198. 
de neuf, de plus grand et de meilleur est aussi indispensable que la mort de l'ancien. L'un se transforme en l'autre, le meilleur rend ridicule et anéantit le pire. Dans le tout du monde et du peuple, il n'est pas de place pour la peur, qui ne peut pénétrer dans la partie qu'en l'isolant du tout, que dans un maillon agonisant, pris séparément du Tout naissant que forment le peuple et le monde, un tout triomphalemente joyeux et ignorant la peur."(p.256)

"Le carnaval (répétons-le, dans l'acception la plus large du terme) affranchissait la conscience de l'emprise de la conception officielle, permettait de jeter un regard neuf sur le monde; un regard dénué de peur, de pitié, parfaitement critique, mais dans le même temps positif et non nihiliste, car il découvrait le principe materiel et généreux du monde, le devenir et le changement, la force invincible et le triomphe éternel du nouveau, l'immortalité du peuple." (p.273)

A diferença, porém, é que, em Vai Passar, com o fim da madrugada abortam-se as promessas de triunfo e cura e a festa acaba por esgotar-se em si mesma. Pode-se facilmente prever a multidão dispersando-se, cada um imerso na saudade recente já projetada em sonho de um próximo carnaval.

\section{CONCLUSÃO}

É possível, agora, responder afirmativamente à pergunta colocada no início: o carnaval da canção possui estrutura carnavalesca do tipo medieval. Porém, falta nele parte de sua essência: o riso aberto e geral. Tomando como parâmetro o carnaval medieval, o carnaval da canção, ao exorcizar do universo ideal da festa os elementos tristes e penosos, ao querer só o bom, sem o ruim, divorcia a expressão da liberdade e seu conteúdo e perde a eficácia como manifestação libertária.

Abro aqui um pequeno parêntese, sugerido pelas alas e blocos evocados na canção, a respeito do carnaval brasileiro divulgado pela mídia. Temse aí uma celebração luxuosa, longamente preparada por escolas de samba, palco de disputa das telas de televisão e de premiações, espaço público para (auto) promoção, algumas críticas, muito erotismo e lavagem de dinheiro. É 
uma festa alegre, mas em que o riso não pode ser considerado paralelo ao oficial, nem libertário, pois é um riso gerado por uma manifestação que obedece a rígidas determinações sociais e as reproduz, na medida em que o grande valor almejado diz respeito a premiações. O carnaval que o Brasil exporta anualmente é um produto de marketing turístico-cultural, uma manifestação teatral artística que pouco ou nada tem de espontâneo. Ele retrata a estrutura de sua versão original, mas é um palco em que barões e napoleões prestam homenagem àqueles que representam. Suas fantasias vestem também a glória efêmera dos indivíduos que, por alguns poucos instantes, destacam-se e confundem-se em homenageador e homenageado. É uma festa em que, ao invés de se rebaixarem as instâncias do poder, opera-se a elevação dos pequenos e oprimidos em seu (único) dia de glória.

Manifestação teatral que cultua personalidades, o carnaval das escolas de samba oferece aos pobres um tira-gosto de riqueza, ou um aperitivo de elevação social, e apresenta à admiração do mundo um modelo de alegria. É, também, passível de premiação - baseada, entre outros itens, em pontualidade, ordem, disciplina -, e freqüentemente termina em confusão e brigas motivadas pela premiação efetuada. Em suma, uma festa que acata o poder vigente e contribui para sua perpetuação, o carnaval das escolas de samba troca o riso escrachado e libertário pela planejada busca do brilho - do troféu, das câmeras, da fama efêmera. Fecho o parêntese.

Embora descreva o desfile de blocos e alas na avenida, Vai Passar não é feita do mesmo barro que os desfiles de escola de samba. Enquanto os últimos promovem, no lugar do rebaixamento, a elevação (dos pequenos, dos homenageados, do público) e apresentam como atração principal luxo, erotismo e sorrisos postiços, a canção contém uma promessa de vitória sobre um período histórico infeliz e de cura dos males do passado, através da ação de um samba popular. Se as escolas de samba traduzem o anticarnaval rabelaisiano, já Vai Passar, à exceção da função do riso e da luminosidade, é fiel às origens medievais, a suas imagens e funções.

Entretanto, a diferente função do riso tem conseqüências, pois determina a apreensão das ambivalências: o grotesco popular, do carnaval medieval, caracterizado pelo amálgama dos opostos, cede lugar a antíteses e contrastes estáticos: de um lado, o cotidiano, a infelicidade, o sofrimento, a penitência; de outro, o camaval, a alegria, a liberdade. Esse quadro, por sua vez, deixa entrever, no carnaval da canção, uma visão romântica de mundo. E aqui torna-se elucidativo resgatar o segundo elemento destoante da visão de mundo presente em Vai Passar e no carnaval medieval/renascentista, apa- 
rentemente desimportante: a luz. Vem corroborar a tese de romantismo a preferência pela noite, já que a festa da canção encerra-se ao amanhecer. "Notons enfin une autre particularité du grotesque romantique: il a une prédilection pour la nuit..., c'est l'obscurité et non la lumière qui le caractérise.)", aponta Bakhtin (p. 50). Riso restrito e celebração noturna são os elementos que afastam o carnaval retratado na canção do quadro carnavalesco medieval/renascentista para o ideário romântico, mais precisamente, alemão

Vai Passar leva a sério a tristeza e a alegria, a vida dura do dia-a-dia e a vida boa do carnaval. Recusa uma e corteja a outra e, então, deixa de ser libertária. Ao apreender ambivalências como antíteses ou contrastes, destaca, valoriza e conserva fixos e estáticos os opostos; ao preferir a noite à luz, distancia-se do quadro de vida e regeneração da festa medieval/renascentista e se aproxima dos desfiles de escolas de samba: com eles, acaba em cinzas ao amanhecer de uma quarta-feira, junto com as promessas que trazia.

\title{
BIBLIOGRAFIA
}

BAKHTINE, M.. L'Oeuvre de François Rabelais et la culture populaire au moyen âge et sous la renaissance. Collection TEL, Gallimard, France, 1988 (1970). HIME, Francis e BUARQUE, Chico. Vai Passar. In HOLLANDA, Chico Buarque de. Chico Buarque, letra e mísica. São Paulo: Companhia das Letras, 1989.

\begin{abstract}
Taking the widely spread belief that Brazilian carnival is the most representative form of carnival as a premise, this text discusses to what extent the song Vai Passar translates a Rabelaisian carnival view of the world, which, according to Bakhtin (1988/1970), leads to freedom and regeneration and includes the following aspects: inversion of the established order, degradation of values, destitution of sacredness, celebration of what is renewable and dynamic, the function of laughter and time and its image system. Drawing from this analysis are some considerations about the nature of the carnival celebration type suggested by the song, the samba school parades, when compared to Middle Age and Renaissance carnival.
\end{abstract}

Key-words: Carmival, popular comic, degradation, grotesque, laughter.

5 Sigo, aqui, a análise de Bakhtin, no mesmo texto, das vertentes do romantismo. 